\title{
Discussion on the Future Development Mode of Firm
}

\author{
Xin Li \\ Xihua University School of Management, Xihua University, Chengdu 610039, China \\ 664984954@qq.com
}

Keywords: Internal and External Cost, the Firm, Firm Scales.

\begin{abstract}
In today's society, firms are divided into large and medium-sized enterprises according to the scale. Looking at the future, how the firm scale will change? What kind of business will exist in the form of it? Based on the nature of the firm, the law of diminishing marginality theory and transaction cost theory, this paper explores the future development of firms in the light of the many factors influencing the development of firms.
\end{abstract}

\section{Introduction}

Firms have been playing a crucial rule in the business market since its concept first appeared. In recent years, with the sharp development of Internet and scientific technology, along with the social economy growth, firm scales have been transformed along its way. The B2B idea proposed by Ma Yun has caught great attention by the society and from where people started to think about what future firm forms would be like in the coming years, and what changes will appear under these circumstances? In this thesis, we will further discuss the evolution of future firm scales and to analyze the development of firm mode and forms.

\section{The Nature of the Firm}

\subsection{The nature of the firm by Coase}

In 1937, R. H. Coase published his article of "The nature of the firm”, in which he analyzed the essence of firm from many aspects and further discussed why do firms exist, do firms correspond with the market price mechanism, and how can firm scales develop, etc.

Since the appearance of firms, the argument about the reason which led to the concept of firm has never been stopped. Some people believed that firms were the outcome of market economy. Some scientists back then had the opinion that due to the development of market economy, division of labour was in high needs, as a result, firms emerged under that circumstances. However, Coase held a different opinion. He thought the reason was rather be that people had various attitude towards risks. The one who could take more risks on things would become the leader and the decision maker among a group of people, on the contrast, others who are more conservative towards things would rather be the followers to work for the leader. Hence the situation above forced the emergence of firms. Besides, Coase also discussed the nature of firms since he thought that transaction cost was tightly related to the appearance of firms. He proposed the thought that the formation of firms could reduce the transaction cost in the market and make more profits.

The scales of firm have close connection to the market competitiveness. In his opinion, the scales of firms would be enlarged under the complete competitive market, while on the other hand, the scopes are limited under the monopoly system. Coase stated that the emergence of firms contributed to allocating resource well in the market, in this way, cost of resource would be reduced, and firms would be able to develop quickly with lower cost. However, the resource was not only influenced by the firm, but also under the control of market, as a result, when one enlarges it's scale, it will increase the cost of transaction and production, and have bad influence on the development of the firm.

In market economy, firms have tight relation with market price. Some people thought that firms 
can decide the market price because when the firm scale has reached to a certain level, the price set by the firm would be accepted by the market. However, Coase still thought that firms could not replace the price mechanism because although the price set by firms could influence the market price, the result is not absolute, which will also be affected by the whole market price. Hence, firms have the ability to adjust price mechanism but cannot totally replace it, the former places a check and balance role on the latter.

\subsection{The theory of Transaction Costs by Oliver Williamson}

The transaction cost is a cost occurred when people in the society making any economic trade in a market. The theory of Transaction Costs was first mentioned by the Noble prize winner R. H. Coase in 1937, in which he further discussed the nature of firms. Later it was developed by Oliver Williamson who finally proposed idea of "Transaction Cost Economics".

In the article of "Transaction Cost Economics" by Oliver Williamson, he states that there are two crucial elements that will have huge impact on the effective of market operation and resource allocation. First of them is the scope of transaction freedom, while another one is the transaction cost. Williamson argues that the degree of freedom of the transaction is measured by the frequency of transactions and the uncertainty of the transaction, and the higher the transaction frequency, the higher the cost of management and the cost of bargaining. And the increase in the frequency of the transaction makes the firm internalize the economic activity so that it saves the transaction costs of enterprises. Transaction cost origins from the Market Failure caused by the human factors and transaction environment factors. It refers to all kinds of costs occurred when making the economic exchange, which can be classified by search and information costs, bargaining costs, policing and enforcement costs, etc.

In the economic system, the division of labor and the operation of the market price function, resulting in professional division of labor phenomenon, and according to the transaction cost theory, the use of market price mechanism costs will be relatively high, so people tend to pursue economic benefits and the formation of an organization - enterprise. According to the transaction cost theory, the implementation of market price mechanism will lead to relatively higher costs, therefore, in order to gain higher economic benefit, the concept of firms appeared.

The cost management of firms is mapped out on the grounds of the overall situation of the firm and it is the outcome in accordance with to the general firm development strategy. Decreasing returns to scale refers to the situation when a proportionate increase in all inputs results in a less than proportionate increase in levels of output. For example, if all inputs are increased by X, outputs will increase by less than $\mathrm{X}$ (a lower proportionate increase). It occurs when factory increases its production scale but cannot coordinate well within all the perspectives of the production that the production efficiency will drop. Western economists have summarised several laws of returns to scale under certain circumstances. When a small start-up company expands its scale sharply, it will land at the stage of increasing returns to scale. However, blindly branching out in order to pursue more profit will lead to opposite results. With the continuous expanding of production scale, the earnings of the firm will tend to remain constant, at this stage persistent enlarging the market domain and market share will result in decreasing returns to scale.

Therefore, we can tell that the firm is an organisation formed in order to reduce the external transaction cost and to seek higher profit at the same time. However, there are still costs for internal management within the firm, which will hinder the economic benefit significantly when it is extremely high. As a result, the competitive advantage of the firm will decrease dramatically.

\section{The Firm under Internal and External Forces}

\subsection{Impact of external transaction cost on firms}

According to R. H. Coase and Oliver Williamson, the firm is the organisation which is formed for the sake of reducing the external transaction cost and seeking for higher economic benefit. External transaction cost has huge impact on firms. When the external transaction cost decreases, 
the profit space will be enlarged so that the firm can obtain more profit. On the contrary, profit space will shrink due to high external transaction cost, which will hinder the development of firms. In order to avoid the negative consequence, firms can take several measures to remain its profit space, for instance, by enhancing equipment technology to reduce the production cost or by decreasing the firm scale to lower internal costs. Therefore, external transaction cost affects not only the firm scales, but also the development strategy.

\subsection{Impact of internal management cost on firms}

Rapid development and expansion demonstrates the firm is leading to a positive direction and can do well to the firm, yet when internal management cost increases significantly at the same time, it will block its development. When the firm scale increases, there will be more personnel than before which will cost more relevantly. If internal management system scale is way too large, it will accounts for a relatively high proportion of inputs which will finally become the obstacle on the way of development.

\section{The Development of Future Firms Polarisation}

\subsection{Firms polarization}

\subsubsection{Globally top firms}

With the rapid growth of economy, the world has arrived in the era of Big Data, where the market transaction cost is much lower than before. The pursuit of obtaining wider stage of development drives firms to expand their scales constantly. However, this will increase the inner cost when which exceeds the market transaction cost, firm profit will decrease. As a result, the expansion of firm scales will be much tough. Figuring out the way to reduce internal cost of a firm is crucial to avoid this issue.

The evolution of Internet and technology enable firms to have lower transaction cost and lower internal management cost at the same time. The digital system will take over the mission of personnel management instead of hiring extra staff for it, which will sharply reduce the personnel cost. Sharply growth of technology and upgraded equipment allow firms to have higher production efficiency and to save energy. Advanced technology, intelligent management methods and scientific management mode can lower the internal cost.

More and more multinational corporations have emerged due economic globalization. A multinational corporation is an organization who owns branches and subsidiaries in one or more countries than their own country by investing directly to participate in multinational economic exchanges. The advantages of utilizing the Internet and advanced scientific internal management system enable transnational corporations to control all the branches and subsidiaries under the centralized leadership, level-to-level administration and uniform cost accounting system, so that they will expand their market share globally and smoothly.

\subsubsection{Micro Business}

In Coase's opinion, both market transactions under the free price system and hierarchical transactions inside enterprises can achieve the optimal resource allocation. If one transaction activity is much more economically sufficient when taken by the internal management than in the external market, then this transaction should be completed by the hierarchical organizations such as firms. The internal management cost of one organization is not permanent as it will increase while the organization scale is expanding. Once the internal management cost surpasses the market transaction cost, the transactions should be taken under the market price system. Organizations like firms emerged since people were willing to cut the external transaction cost and to obtain higher economic. However, when the internal management cost exceeds external transaction cost, how can the firm thrive with relatively low economic benefit?

As far as it is concerned, thanks to the blossom of Internet technology, the level of technology standardization and compatibility is booming along the way. Under this circumstances, people can 
realize the purpose of knowledge sharing and exchanging without establishing a rather more formal form of organization system such as equity joint. The enhancement of technology standardization demonstrates that R\&D cooperation among enterprises can be legally protected as it can be inserted as clause into the contracts beforehand.

On the other hand, with the intellectual property protection system is sound, the transaction costs of enterprise signing, implementing contractual cooperation are also significantly reduced. At this time even if the cost of equity-style cooperation remains unchanged, the reduction of contractual cooperation costs also lead to contractual cooperation to become a mainstream. And with the development of e-commerce, greatly improved the enterprises in supply, inventory, transportation, information flow and other aspects of the benefits. Through e-commerce, business enterprises can timely and accurately access to consumer information, in order to order accurately, reduce inventory, and promote sales through the network to improve efficiency, reduce costs and to obtain greater benefits. The success of Alibaba is the successful use of e-commerce in the enterprise.

Recently, Ma Yun made the B2B caused great attention in the economy. In 2014, US corporatelevel services received $40 \%$ of US venture capital and Toc received the remaining 60\%. Looking back on the development of the Internet for the past decade, the today of the United States, perhaps to be China's tomorrow. Promoting the development of national strength, the ToB depth of entrepreneurship will be the next "outlet." In view of this, the future development of enterprises may be aiming at the development of contract-based enterprises. Enterprise form is no longer fixed, and people can allocate resources well by utilizing the platform of the Internet, and to establish the corporate form by generating contracts for transactions.

\subsection{Polarized enterprises coexist in the future}

With the development of social economy and science and technology, not only the external transaction costs can be reduced, so are the internal transaction costs. Then with the internal forces and external forces, how will the enterprises develop? Will they benefit from the reduction of external transaction costs to form a contractual scattered enterprises, or with the reduction of internal costs to form a large enterprise? The truth is that the business will show polarization, and the two poles exist at the same time. In this era of digital information revolution, along with the advent of the era of global business competition, there will be a large-scale elimination in the market - kicking out the inferior enterprises, leaving the winning enterprises. And for the enterprises remained, they will continue to expand the scale in the era of globalization, with the implementation of centralized ties, hierarchical management, unified accounting, and to thrive as global large firms. Among all these large enterprises, there are also the existence of micro-enterprises, who survive in between the large enterprises, doing some scattered business. In general, the future business circle will consist of large global firms as well as the micro-enterprises, which means that it is a large circle with various small circles inside.

\section{References}

[1] Coase, Ronald (1937). "The Nature of the Firm". Economica. Blackwell Publishing. 4 (16): 386-405. doi:10.1111/j.1468-0335.1937.tb00002.x. JSTOR 2626876.

[2] Williamson, Oliver. and Winter, Sidnecy G., "The Nature of the Firm, Origins, Evolution, and Development”, 1993

[3] Sun Xuanzhong. Introduction to modern enterprises. Beijing: China University of Political Science and Law Press, 2004.1

[4] Chen Mingxing. The world's top enterprises 18 competition law. Beijing: China Textile Publishing House, 2005.1

[5] Zheng Jianzhuang, Wang Peicai. Fundamentals of Economics. Beijing: Tsinghua University Press, 2009.9

[6] Yin Yu. On the meaning of Coase theorem [J]. Commercial economy, 2005, 08 